\title{
ANALISA ALIRAN DAYA PADA JARINGAN DISTRIBUSI 20 KV PT. PLN (PERSERO) SEBATIK MENGGUNAKAN SOFTWARE ETAP POWERSTATION 12.6.0
}

\author{
Sumardi ${ }^{1}$, Patria Julianto ${ }^{2}$ \\ ${ }^{1,2}$ Teknik Elektro, Universitas Borneo Tarakan, Tarakan, Kalimantan Utara, Indonesia \\ 1sumardi.borneodgmail.com \\ ${ }^{2}$ patria81@gmail. com
}

\begin{abstract}
Along with the development of various sectors of local development using electrical energy as an infrastructure supporting community activities. Electric power system that is expected to be a reliable and quality systems. Therefore, to determine the condition of the Electric power system necessary to do research related to electric power flow analysis with the aim to determine the condition of the system under normal circumstances.

The research was conducted at PT. PLN (Persero) Sebatik. PT. PLN (Persero) Sebatik plant has a total capacity of $2 \mathrm{MW}$. Generated power for public purposes Sebatik. The data used in this am of PT. PLN Sebatik, generated data, data channel and load data. The study was conducted by taking the case of base load and peak load. To simulate and analyze the power system, in this study used a software ETAP PowerStation 12.6.0 with power flow studies using Newton - Raphson method.
\end{abstract}

Keywords- Power Flow Analysis, Electrical Power System, Drop Voltage

Intisari- Seiring dengan perkembangan pembangunan daerah dari berbagai sektor menggunakan energi listrik sebagai infrastruktur penunjang kegiatan masyarakat. Sistem tenaga listrik yang ada diharapkan merupakan sistem yang handal dan berkualitas. Oleh karena itu untuk mengetahui kondisi sistem tenaga listrik perlu dilakukan penelitian yang berhubungan dengan analisa aliran daya listrik dengan tujuan agar dapat mengetahui kondisi sistem dalam keadaan normal.

Penelitian dilakukan di PT. PLN (Persero) Sebatik. PT PLN (Persero) Sebatik memiliki total kapasitas Pembangkit sebesar 2 MW. Daya yang dibangkitkan untuk keperluan masyarakat Sebatik. Data yang digunakan dalam penelitian ini berupa diagram segaris PT. PLN Sebatik, data pembangkit, data saluran dan data beban. Penelitian dilakukan dengan mengambil kasus beban dasar dan beban puncak. Untuk mensimulasikan dan menganalisa sistem tenaga listrik, dalam penelitian ini digunakan software ETAP PowerStation 12.6.0 dengan studi aliran daya menggunakan metode Newton-Raphson

Kata Kunci-Analisa aliran daya, Sistem Tenaga Listrik, Jatuh Tegangan.

\section{PENDAHULUAN}

Kecamatan Sebatik memiliki jumlah penduduk lebih dari 22.283 jiwa dengan kepadatan penduduk sebanyak 195,5 jiwa/km2 dan luas wilayah 104,42 km2. Pulau ini merupakan salah satu Pulau terluar yang menjadi prioritas utama pembangunan karena berbatasan langsung dengan Negara tetangga. Salah satu pembangunan yang ada khususnya pengembangan listrik di pulau Sebatik.

Seiring dengan perkembangan semua kegiatan pembangunan khususnya di pulau Sebatik dari berbagai sektor menggunakan energi listrik sebagai salah satu infrastruktur penunjang kegiatan masyarakat Sebatik. Sistem tenaga listrik yang ada diharapkan merupakan sistem yang handal dan berkualitas tinggi berkaitan dengan suplai energi listriknya

Untuk mengetahui kondisi teknis sistem kelistrikan dilakukan analisa terhadap komponen sistem tenaga listrik yang meliputi pembangkit, saluran Distribusi, dan beban terpasang. Kita dapat menggunakan metode perhitungan aliran daya dalam analisa sistem tenaga untuk mengetahui besarnya nilai parameter-parameter di setiap Bus sistem yang meliputi tegangan, daya, arus, dan besarnya sudut fasa.[4]

\section{LANDASAN TEORI}

\section{A. Jaringan Pada Sistem Distribusi Primer}

Jaringan Pada sistem Distribusi tengah menengah Primer 20kV dapat dikelompokkan menjadi beberapa model diantaranya, yaitu jaringan Radial, Jaringan hantaran penghubung (Tie Line),Jaringan Lingkaran (loop), Jaringan Spindel.

\section{B. Daya}

Daya adalah energi yang dikeluarkan untuk melakukan usaha. Dalam sistem tenaga listrik, daya dinyatakan dengan watt dan $\mathrm{P}$ adalah rata rata atau disebut daya aktif dengan satuan Watt, sedangkan Q adalah daya reaktif dalam satuan Var. dalam rangkaian AC satu fasa dapat ditarik kesimpulan rumus untuk daya pengukuran pada rangkaian adalah sebagai berikut :[2]

$P=V . I \operatorname{Cos} \varphi$

atau

$Q=V . I \operatorname{Sin} \varphi$

Dengan :

$P=$ Daya dalam Watt $(\mathrm{W})$ 
$Q=$ Daya reaktif dalam var

$V=$ Tegangan dalam Volt $(\mathrm{V})$

$I=$ Arus dalam Ampere $(\mathrm{A})$

$\operatorname{Cos} \varphi=$ Faktor daya

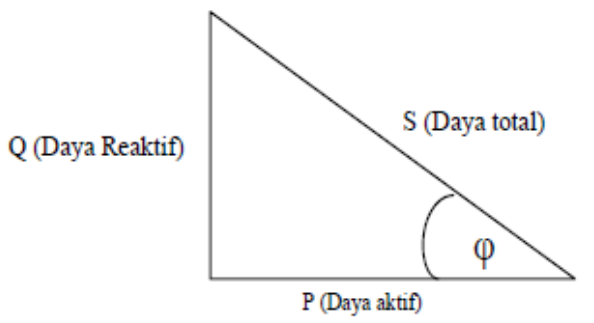

Gambar 1. Hubungan antara daya

\section{Segitiga Daya}

Untuk menentukan daya pada suatu rangkaian AC yang terdiri dari daya aktif (P) dan daya reaktif (Q) dipergunakan segitiga siku siku[2]

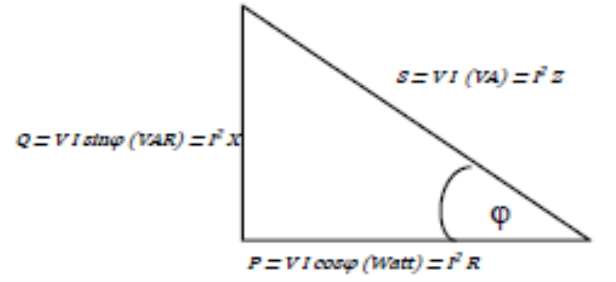

Gambar 2. Rumus Segitiga daya

Hasil kali $V$ dan $I$

$V I=$ Daya Total $S$, Volt Ampere

$\mathrm{S}=\sqrt{\mathrm{P} 2+\mathrm{Q} 2}$

Rugi-rugi daya Pada saluran

$\mathrm{P}_{\text {loss }}=\mathrm{I}^{2} \mathrm{Z}$

\section{Studi Aliran Daya}

Studi aliran daya merupakan studi untuk mendapatkan informasi mengenai Aliran daya pada kondisi saat operasi sistem. Informasi ini sangat dibutuhkan guna mengevaluasi unjuk kerja sistem Tenaga dan menganalisis kondisi pembangkitan maupun pembebanan.

Analisa aliran daya (Load Flow Analysis) dilakukan untuk mengetahui besarnya tegangan bus, faktor daya dari cabang, arus dan aliran daya yang terjadi pada saluran dalam sistem. ETAP PowerStation Load Flow Analysis adalah program simulasi untuk tujuan analisa aliran daya. Sistem yang dapat dianalisa adalah sistem radial maupun loop.[4],[2]

\section{E. Kualitas Daya}

Kualitas daya listrik adalah tenaga listrik yang andal, energi listrik dengan kualitas yang baik dan memenuhi standar, mempunyai kontribusi yang sangat penting bagi kehidupan masyarakat jaman sekarang. Pengertian ini didasarkan dari tiga komponem penting tentang kualitas daya listrik, yaitu kontinuitas, flekdibel, dan efisiensi.
Dengan adanya kualitas daya yang baik maka faktor ekonomis atau biaya dapat ditekan seminimal mungkin. Terdapat beberapa definisi yang berbeda terhadap pengertian tentang kualitas daya listrik, tergantung kerangka acuan yang digunakan dalam mengartikan masalah tersebut. Daya adalah suatu nilai dari energi listrik yang ditransmisikan dan didistribusikan (Roger C.Dugan, 1996).

\section{F. Konsep Perhitungan Aliran daya}

Perhitungan aliran daya pada dasarnya adalah menghitung besaran tegangan $V$ dan sudut fasa tegangan $\delta$ pada setiap G.I. Hasil perhitungan ini digunakan untuk menghitung besar aliran daya aktif $P$ dan daya reaktif $Q$ di setiap peralatan transmisi, besarnya daya aktif $P$ dan daya reaktif $Q$ yang harus dibangkitkan setiap pusat pembangkit serta jumlah rugi-rugi di sistem

Berdasarkan parameter-parameter yang diketahui, maka bus pada suatu sistem tenaga listrik diklasifikasikan dalam 3 jenis yaitu Bus beban, Bus pembangkit, Bus swing.[1]

\section{G. Perhitungan Aliran Daya menggunakan ETAP Powerstation}

Pada perhitungan aliran daya menggunakan ETAP akan dihitung tegangan rel, faktor daya, arus dan aliran daya yang melalui sistem tenaga listrik. Program dapat menggunakan sumber tenaga ayun (swing), pengaturan tegangan dan tanpa pengaturan tegangan dengan banyak generator dan peralatan. Program ini dapat digunakan untuk jaringan loop maupun radial. Metode perhitungan yang berbeda dapat dipilih untuk memperoleh hasil perhitungan yang terbaik. Pada ETAP terdapat 3 metode perhitungan aliran daya yaitu Newton-Raphson, fastdecoupled dan accelerated Gauss-Seidel. Ketiganya mempunyai karakteristik konvergensi yang berbeda. Metode yang akan digunakan dapat dipilih dari ketiganya, tergantung konfigurasi sistem, pembangkitan, kondisi beban dan tegangan awal rel. Indeks presisi pada setiap metode dapat kita tentukan sendiri. Untuk metode Newton-Raphson dan fast-decoupled biasanya adalah 0,0001 sedangkan untuk metode accelerated Gauss-Seidel umumnya menggunakan indeks presisi 0,000001 dengan faktor akselerasi sebesar 1,45.[3]

\section{METODE PENELITIAN}

Dalam penelitian ini lokasi yang diambil yaitu di PT. PLN (Persero) Sebatik Cabang Berau Kabupaten Nunukan. Pada tahap ini penulis mengumpulkan data diagram segaris (Single Line Diagram) PT. PLN (Persero) Sebatik, data pembangkit, data saluran penghantar, dan data beban.

Dalam pengolahan data di lakukan beberapa tahap yaitu pengambilan data, membuat pemodelan sistem tenaga listrik berdasarkan diagram segaris menggunakan software ETAP Powerstation 12.6.0, Melakukan analisa kualitas daya pada kondisi awal dan kondisi puncak, menganalisa dan membandingkan perubahan yang terjadi 
dari kondisi beban, dan terakir menarik kesimoulan dari penelitian yang telah dilakukan.

\section{A. Data Pembangkit}

Data Pembangkit meliputi daya aktif, reaktif, dan dayasemu

Tabel I

Data pembangkit beban dasar

\begin{tabular}{|c|c|c|c|c|c|}
\hline No & $\begin{array}{c}\text { Nama } \\
\text { Generator }\end{array}$ & Jumlah & $\begin{array}{c}\text { Daya Output } \\
(\mathrm{kW})\end{array}$ & $\begin{array}{c}\text { Daya Kompeks } \\
(\mathrm{KVA})\end{array}$ & $\begin{array}{c}\text { Daya Reaktif } \\
\text { (KVAR) }\end{array}$ \\
\hline 1 & DEUTZ MWM & 1 & 290 & 341.1764706 & 177.4117647 \\
\hline 2 & MAN D2842 & 1 & 150 & 176.4705882 & 91.76470588 \\
\hline 3 & MAN D2842 & 1 & 250 & 294.1176471 & 152.9411765 \\
\hline 4 & MAN D2842 & 1 & 240 & 282.3529412 & 146.8235294 \\
\hline 5 & DEUTZ MWM & 1 & 0 & 0 & 0 \\
\hline 6 & MAN D2842 & 1 & 0 & 0 & 0 \\
\hline 7 & CUMMING & 1 & 0 & 0 & 0 \\
\hline 8 & CUMMNGS & 1 & 0 & 0 & 0 \\
\hline 9 & PLTS & 1 & 120 & 141.1764706 & 73.41176471 \\
\hline 10 & PLTMG & 1 & 0 & 0 & 0 \\
\hline 11 & Total & 10 & 1050 & 1235.294118 & 642.3529412 \\
\hline
\end{tabular}

Tabel II

Data pembangkit beban puncak

\begin{tabular}{|c|c|c|c|c|c|}
\hline No & $\begin{array}{c}\text { Nama } \\
\text { Generator }\end{array}$ & Jumlah & $\begin{array}{c}\text { Daya Output } \\
(\mathrm{kW})\end{array}$ & $\begin{array}{c}\text { Daya Kompeks } \\
\text { KVA }\end{array}$ & $\begin{array}{c}\text { Daya Reaktif } \\
\text { KVAR }\end{array}$ \\
\hline 1 & DEUTZ MWM & 1 & 320 & 376.4705882 & 195.7647059 \\
\hline 2 & MAN D2842 & 1 & 310 & 364.7058824 & 189.6470588 \\
\hline 3 & MAN D2842 & 1 & 300 & 352.9411765 & 183.5294118 \\
\hline 4 & MAN D2842 & 1 & 300 & 352.9411765 & 183.5294118 \\
\hline 5 & MAN D2842 & 1 & 300 & 352.9411765 & 183.5294118 \\
\hline 6 & DEUTZ MWM & 1 & 290 & 341.1764706 & 177.4117647 \\
\hline 7 & CUMMINGS & 1 & 0 & 0 & 0 \\
\hline 8 & CUMMINGS & 1 & 0 & 0 & 0 \\
\hline 9 & PLTS & 1 & 0 & 0 & 0 \\
\hline 10 & PLTMG & 1 & 0 & 0 & 0 \\
\hline \multicolumn{2}{|c|}{ Total } & 10 & 1820 & $\mathbf{2 1 4 1 . 1 7 6 4 7 1}$ & 1113.411765 \\
\hline
\end{tabular}

Daya Semu

$$
\mathrm{S} \quad=290 / 0,85=341,1765 \mathrm{kVA}
$$

Daya Reaktif

$$
\begin{aligned}
\mathrm{Q} & =341.1765 \times \sin 31,73= \\
& =341.1765 \times 0.52=177.411
\end{aligned}
$$

Sudut fasa

$$
\begin{aligned}
\cos \varphi & =0.85 \\
\varphi & =\cos -10.85 \\
\sin \varphi & =31.7883 \\
& =0.52
\end{aligned}
$$

\begin{tabular}{|c|c|c|c|c|}
\hline $\mathrm{N}_{0}$ & Feeder & $\begin{array}{l}\text { Daya Output } \\
\text { (kIV) }\end{array}$ & $\begin{array}{c}\text { Daya Semu } \\
\text { (kVA) }\end{array}$ & $\begin{array}{c}\text { Daya Reaktif } \\
\text { (kVAR) }\end{array}$ \\
\hline 1 & 1 & 574 & 675.2941176 & 351.1529412 \\
\hline 2 & 2 & 678 & 797.6470588 & 414.7764706 \\
\hline 3 & 3 & 568 & 668.2352941 & 347.4823529 \\
\hline Jumlah & & 1820 & 2141.176471 & 1113.411765 \\
\hline
\end{tabular}

B. Data Beban

Tabel III

Data beban malam tiap feeder

\begin{tabular}{|c|c|c|c|c|c|c|c|c|}
\hline \multirow[b]{2}{*}{ No } & \multirow[b]{2}{*}{ Feeder } & \multicolumn{5}{|c|}{$\mathrm{A} 3 \mathrm{C}$} & \multirow{2}{*}{$\begin{array}{c}\mathrm{A} 3 \mathrm{CS} \\
240 \\
\mathrm{~mm} 2\end{array}$} & \multirow[b]{2}{*}{$\begin{array}{l}\text { Jumlah } \\
\text { (KMS) }\end{array}$} \\
\hline & & $50 \mathrm{~mm} 2$ & $\begin{array}{c}70 \\
\mathrm{~mm} 2\end{array}$ & $\begin{array}{c}95 \\
\mathrm{~mm} 2\end{array}$ & $\begin{array}{c}120 \\
\mathrm{~mm} 2\end{array}$ & $\begin{array}{c}150 \\
\mathrm{~mm} 2\end{array}$ & & \\
\hline 1 & 1 & $11.3 \mathrm{KMS}$ & - & - & - & - & - & 11.3 \\
\hline 2 & 2 & $6.2 \mathrm{KMS}$ & - & - & - & - & - & 6.2 \\
\hline 3 & 3 & $42.4 \mathrm{KMS}$ & - & - & - & - & - & 42.4 \\
\hline 4 & $\begin{array}{l}\text { Feeder } \\
\text { expres }\end{array}$ & - & - & - & - & 43 & & 43 \\
\hline
\end{tabular}

Tabel IV

Data beban siang tiap feeder

\begin{tabular}{|c|c|c|c|c|}
\hline No & Feeder & $\begin{array}{c}\text { Daya Output } \\
(\mathrm{kW})\end{array}$ & $\begin{array}{c}\text { Daya Semu } \\
\text { (kVA) }\end{array}$ & $\begin{array}{c}\text { Daya Reaktif } \\
\text { (kVAR) }\end{array}$ \\
\hline 1 & 1 & 448 & 527.0588235 & 274.0705882 \\
\hline 2 & 2 & 356 & 418.8235294 & 217.7882353 \\
\hline 3 & 3 & 246 & 289.4117647 & 150.4941176 \\
\hline Jumlah & \multicolumn{5}{|l}{ Sumber: Data Primer PT. PLN Sebatik, 2015 } & 1235.294118 & 642.3529412 \\
\hline
\end{tabular}

C. Data Saluran Penghantar

Tabel V

Data panjang saluran dan diameter kabel

Semua penghantar memakai jenis kabel NYY dengan bahan Alumunium dan dengan ukuran pada Tabel 5, kecuali untuk PLTMG ke Feeder 2 dan Feeder 3 memakai kabel jenis XLPE dengan bahan penghantar Alumunium.

\section{HASIL DAN PEMBAHASAN}

A. Sistem Tenaga Listrik PT. PLN (Persero) Sebatik

Penyaluran sistem tenaga listrik PT. PLN (Persero) Sebatik cabang berau ke beban listrik dengan mengoperasikan pembangkit listrik secara paralel. Sistem paralel digunakan agar daya listrik yang dihasilkan oleh pembangkit sesuai dengan beban listrik yang ada. Daya listrik yang disalurkan ke beban listrik melalui penyulang (feeder). Sistem tenaga Listrik PT. PLN (Persero) Sebatik cabang Berau dibagi dalam 3 penyulang (feeder). Total daya yang dibangkitkan dari semua pembangkit yang beroperasi di PT. PLN (Persero) Sebatik cabang Berau

\begin{tabular}{|c|c|c|c|c|c|c|}
\hline \multicolumn{2}{|c|}{ BUS } & \multicolumn{2}{|c|}{ Lead/Behan } & \multicolumn{3}{|c|}{ Total Bus Lead } \\
\hline ID & KV & MW & Mvar & MVA & PF & Amp \\
\hline Bus Belen.1 & 20 & 0.442 & 0.274 & 0519 & 85 & 15.1 \\
\hline Bus Beten 2 & 20 & 0.354 & 0.219 & 0.417 & 85 & 12 \\
\hline Bus Belen 3 & 20 & 0.237 & 0.147 & 0.279 & 85 & 8.2 \\
\hline
\end{tabular}
saat ini yaitu $2170 \mathrm{~kW}$. $\operatorname{Cos} \varphi$ pada PT.PLN (Persero) Sebatik cabang Berau sebesar 0.85 dan $\operatorname{Sin} \varphi$ 0.52.[5]

B. Hasil Simulasi ETAP Beban Dasar Pukul 12:00 WITA

Tabel VI

Data bus beban

Dari hasil simulasi aliran daya, Data Tabel 4.1 Menampilkan hasil saat beban dasar siang pukul 12.00 WITA tentang kondisi beban di PT. PLN Sebatik. Berdasarkan data pada Tabel 6, dapat dilihat bahwa semua bagian beroperasi dalam kondisi normal dalam arti tidak beroperasi melebihi beban yang telah ditentukan. 
Tabel VII

Data trafo

\begin{tabular}{|c|c|c|c|c|c|c|}
\hline \multicolumn{2}{|c|}{ Branch/Calang } & \multicolumn{5}{|c|}{ Trandformaber } \\
\hline \multirow{2}{*}{ ID } & \multirow{2}{*}{ Type } & \multirow{2}{*}{$\frac{\text { Kapasitas }}{\text { MVA }}$} & \multicolumn{2}{|c|}{ Loaling Iopu } & \multicolumn{2}{|c|}{ Loading Outpat } \\
\hline & & & MVA & $\%$ & MVA & $\%$ \\
\hline STEP UP_2 & Tamoformalot & 0.63 & 0.358 & 56.8 & 0.351 & 55.6 \\
\hline$S T E P U_{-} 3$ & Tamformatiof & 0.63 & 0.293 & 46.4 & 0.288 & 45.7 \\
\hline STEP UP_4 & Temoformatiof & 0.63 & 0.175 & 27.8 & 0.174 & 27.6 \\
\hline STEP UP_S & Tansormatot & 0.63 & 0.281 & 44.6 & 0.276 & 43.9 \\
\hline
\end{tabular}

Dari hasil simulasi aliran daya, data Tabel 7 Menampilkan hasil saat beban dasar Pukul 12.00 WITA tentang kondisi masing-masing transformator dan kapasitas dari tranformator, bahwa transformator dalam kondisi yang normal, yaitu besarnya daya kompleks (VA) yang keluar tidak melebihi kapasitas dari masing-masing transformator

Tabel VIII

Daya yang mengalir pada bus

\begin{tabular}{|c|c|c|c|c|c|c|c|}
\hline \multicolumn{2}{|c|}{ Bus $\mathbb{D}$} & \multicolumn{2}{|c|}{ DAYA } & \multicolumn{2}{|c|}{$B m \mathbb{D}$} & \multicolumn{2}{|c|}{ DAYA } \\
\hline $\begin{array}{l}\text { Duri } \\
\text { Bus }\end{array}$ & $\mathrm{K} \oplus \mathrm{Bms}$ & P & Q & Daribus & $\mathrm{K}_{0} \mathrm{bus}$ & P & $Q$ \\
\hline 1 & 6 & 296 & 202 & 6 & 1 & 291 & 195 \\
\hline 2 & 8 & 250 & 152 & 8 & 2 & 247 & 147 \\
\hline 3 & 9 & 150 & 91 & 9 & 3 & 149 & 89 \\
\hline 4 & 9 & 240 & 146 & 9 & 4 & 237 & 142 \\
\hline 5 & 9 & 120 & 73 & 9 & 5 & 120 & 73 \\
\hline 6 & 11 & 291 & 195 & 11 & 6 & 291 & 199 \\
\hline 7 & Bus Bobun 2 & 356 & 220 & $B=$ Bobm 2 & 7 & 354 & 219 \\
\hline 7 & Bus Bobun 3 & 242 & 150 & $B=B a b m 3$ & 7 & 237 & 147 \\
\hline 8 & Bus Boban 1 & 446 & 276 & $B=$ Bobmel & 8 & 442 & 274 \\
\hline 9 & 8 & 199 & 129 & 8 & 9 & 199 & 129 \\
\hline 9 & 12 & 998 & 370 & 12 & 9 & 598 & 370 \\
\hline 10 & 9 & 0 & 0 & 9 & 10 & $\overline{0}$ & 0 \\
\hline 11 & 9 & 291 & 195 & 9 & 11 & 291 & 195 \\
\hline 12 & 7 & 598 & 370 & 7 & 12 & 398 & 370 \\
\hline
\end{tabular}

Dari hasil Simulasi alirandaya, data Tabel 8 Menampilkan hasil saat beban dasar tentang besarnya daya yang mengalir pada tiap-tiap bus. berdasarkan data tersebut bisa dikatakan kondisi sistem tenaga listrik PT. PLN Persero Sebatik pada saat beban dasar pagi pukul 12.00 WITA dalam kondisi yang normal

Tabel IX

Rugi - rugi daya

\begin{tabular}{|c|c|c|c|c|}
\hline \multirow{2}{*}{ ID } & \multirow{2}{*}{ Type } & \multicolumn{2}{|c|}{ Losses } & \multirow{2}{\text{Tegangan}}{$\begin{array}{c}\text { Jatuh Vd } \\
(\%)\end{array}$} \\
\cline { 3 - 4 } & & $\mathbf{k W}$ & $\mathbf{k V A r}$ & \\
\hline Line2 & Kabel & 1.7 & 1 & 0.46 \\
\hline Line3 & Kabel & 5.2 & 3.1 & 2.15 \\
\hline Line1 & Kabel & 4.8 & 2.8 & 1.06 \\
\hline STEP UP_2 & Trafo & 4.5 & 6.8 & 0.34 \\
\hline STEP UP_3 & Trafo & 3 & 4.6 & 0.76 \\
\hline STEP UP_4 & Trafo & 1.1 & 1.7 & 1.43 \\
\hline STEP UP_5 & Trafo & 2.8 & 4.2 & 0.83 \\
\hline \multicolumn{2}{|c|}{ Losses } & 23.1 & 24.2 & \\
\hline
\end{tabular}

Berdasarkan hasil simulasi aliran daya, data Tabel 9 Menampilkan hasil total besarnya rugi-rugi daya Sebesar $23.1 \mathrm{~kW}$ dan $24.2 \mathrm{kVar}$.
Tabel X

Hasil simulasi kerugian antar saluran

\begin{tabular}{|c|c|c|c|}
\hline \multicolumn{2}{|c|}{ Bus ID } & \multicolumn{2}{|c|}{ Kerugian } \\
\hline Dari & $\mathrm{Ke}$ & $\begin{array}{c}\mathrm{P} \\
(\mathrm{kW})\end{array}$ & $\begin{array}{c}\mathrm{Q} \\
(\mathrm{kVAR})\end{array}$ \\
\hline 1_Bus DEUTZ.5 & 6_MG/DM 1-A & 5 & 7 \\
\hline 2_Bus MAN.6 & 8_MG DM 1-A & 3 & 5 \\
\hline 3_Bus MAN.7 & 9_OPEN BUSBAR & 1 & 2 \\
\hline 4_Bus MAN.8 & 9_OPEN BUSBAR & 3 & 4 \\
\hline 5_Bus PLTS & 9_OPEN BUSBAR & 0 & 0 \\
\hline 6_MG / DM 1-A & 11_Bus MG & 0 & 0 \\
\hline 7_MG / DM -1A & Bus Beban.2 & 2 & 1 \\
\hline 7_MG / DM -1A & Bus Beban. 3 & 5 & 3 \\
\hline 8_MG DM 1-A & Bus Beban.1 & 4 & 2 \\
\hline 9_OPEN BUSBAR & 8_MG DM 1-A & 0 & 0 \\
\hline 9_OPEN BUSBAR & 12_BusMG & 0 & 0 \\
\hline 10_Siemens & 9_OPEN BUSBAR & 0 & 0 \\
\hline 11_Bus MG & 9_OPEN BUSBAR & 0 & 0 \\
\hline 12_BusMG & 7_MG / DM -1A & 0 & 0 \\
\hline \multicolumn{2}{|c|}{ TOTAL } & 23 & 24 \\
\hline
\end{tabular}

C. Pemodelan Sistem Tenaga Listrik

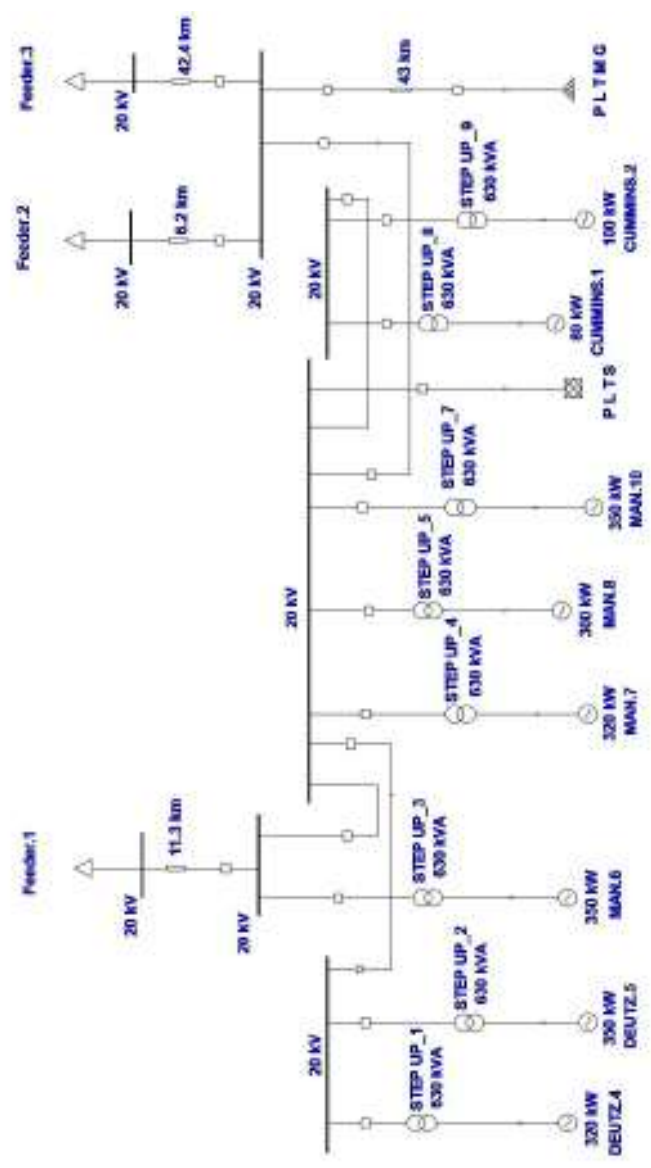

Gambar 3. Diagram segaris PT. PLN (Persero) Sebatik ETAP 12.6.0

D. Perbandingan Hasil dua Kondisi

Dari hasil Penelitian yang telah dilakukan dapat dibandingkan hasil dari total pembangkitan dan rugi-rugi daya dari dua kondisi yaitu pada kondisi Beban dasar dan kondisi beban puncak. 


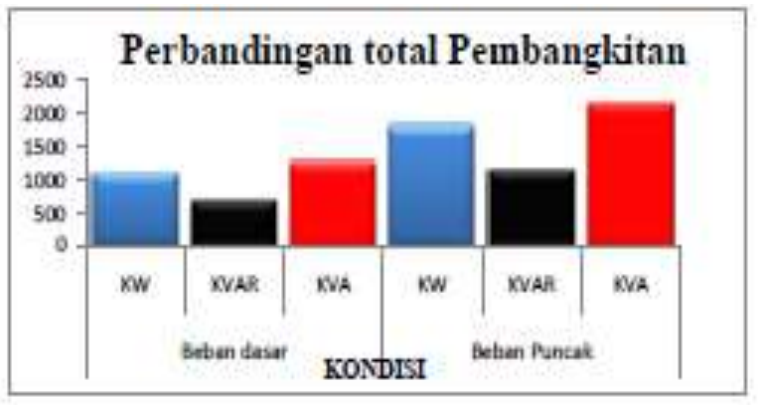

Gambar 4. Grafik Perbandingan Total Pembangkitan

\section{KESIMPULAN}

Berdasarkan hasil percobaan simulasi studi aliran daya tentang Analisa aliran daya pada jaringan distribusi 20kV PT. PLN (Persero) Sebatik pada Kondisi beban dasar Siang dan beban puncak Malam dengan menggunakan software ETAP PowerStation 12.6.0 diambil beberapa kesimpulan :

- Daya yang mengalir ke setiap beban/ Feeder tergantung dari beban yang terpasang.

- Pada kondisi beban dasar dan Beban Puncak dapat diketahui besarnya daya aktif yang disalurkan adalah $1.056 \mathrm{~kW}$ lebih kecil dari kondisi malam sebesar $1810 \mathrm{~kW}$.

- Diketahui besarnya rugi-rugi daya pada kondisi Siang sebesar 0.023 MW dan 0.024 MVAr, pada kondisi Malam rugi-rugi daya sebesar $0.067 \mathrm{MW}$ dan 0.65 MVAr lebih Besar dari kondisi Siang,

- $\quad$ Pada kondisi beban puncak malam terjadi undervoltage pada beberapa bagian Feeder yaitu jatuh Tegangan terbesar terjadi pada Feeder.3 sebesar $\mathrm{Vd} \%=5 \%$ dari tegangan normal $20 \mathrm{kV}$ turun menjadi 19.061 KV. Penurunan tegangan tersebut terjadi karena jarak sumber dengan pembebanan relatif jauh.

- Jatuh tegangan terkecil terjadi pada feeder.2 sebesar $\mathrm{Vd} \%=1 . \%$ dari tegangan normal $20 \mathrm{kV}$ turun menjadi $19.852 \mathrm{kV}$.

- Penurunan tegangan tersebut masih dalam batas toleransi SPLN yaitu tidak lebih dari 5\% dan untuk Tegangan Lebih tidak kurang dari $10 \%$ untuk Jatuh Tegangan dari tegangan nominal

\section{UCAPAN TERIMA KASIH}

Terima kasih penulis ucapkan kepada segenap pihak yang secara langsung maupun tidak langsung telah berkontribusi baik terhadap proses penyusunan tulisan ini maupun dalam proses publikasinya. Terima kasih kepada para autor yang naskahnya penulis jadikan sebagai referensi.

\section{REFERENSI}

[1] Afandi A.N. ,Opersasi Sistem tenaga Listrik Berbasis EDSA, Penerbit Gava Media, Yogyakarta 2010

[2] Hadi saadat,"Power Sistem Analysis", McGraw-Hill Inc, 1999

[3] Julianto, Patria "Optimisasi Penentuan Lokasi dan Ukuran Kapasitor Pada Sistem Distribusi Menggunakan Improved Adaptive Genetic Algorithm" Tesis. ITS, 2010 Multa P, Lesnanto "Modul Pelatihan ETAP” Jurusan Teknik Elektro Dan Teknologi Informasi Universitas Gadjah Mada, Yogyakarta 2013

[4] Sulasno, Ir."Analisis Sistem Tenaga", Semarang: Badan Penerbit Universitas Diponegoro, 1993

[5] Tanato Yusak "Visualisasi Sistem Tenaga Listrik Menggunakan PowerWorld Simulator" Penerbit GRAHA ILMU Yogyakarta 2013 